\title{
ON THE ABSOLUTE NÖRLUND SUMMABILITY FACTORS OF INFINITE SERIES
}

\author{
S. M. MAZHAR
}

\begin{abstract}
A general theorem on absolute Nörlund summability factors of infinite series has been obtained. The theorem includes, as special cases, a number of well-known results. Several new results can also be deduced from it.
\end{abstract}

1. Let $p_{n} \geqq 0, q_{n}>0, Q_{n}=q_{0}+q_{1}+\cdots+q_{n} \rightarrow \infty, P_{n}=p_{0}+p_{1}+\cdots+p_{n}$ and $P_{-1}=p_{-1}=Q_{-1}=0$. Let $\sum a_{n}$ be a given infinite series with $s_{n}$ as its $n$th partial sum. The series $\sum a_{n}$ is said to be summable $\left|N, p_{n}\right|$ if $t_{n} \in B V$, where $t_{n}=P_{n}^{-1} \sum_{k=0}^{n} p_{n-k} s_{k}, P_{n} \neq 0$. It is said to be summable $\left|\bar{N}, q_{n}\right|$ if $T_{n} \in B V$, where $T_{n}=Q_{n}^{-1} \sum_{k=0}^{n} q_{k} s_{k}$.

It is well known that necessary and sufficient conditions for the method $\left(N, p_{n}\right)$ to be absolutely regular are:

$$
\begin{gathered}
p_{n} / P_{n} \rightarrow 0, \quad n \rightarrow \infty, \\
\sum_{n=0}^{\infty}\left|\frac{P_{n+1-k}}{P_{n+1}}-\frac{P_{n-k}}{P_{n}}\right|<C \quad \text { for all } k \geqq 1, \\
\quad \text { where } C \text { is a positive constant. }
\end{gathered}
$$

2. The following theorems concerning summability factors are known.

THEOREM A [1]. The necessary and sufficient conditions that $\sum a_{n} \varepsilon_{n}$ be summable $|N, 1 / n+1|$ whenever $\sum a_{n}$ is summable $|C, 1|$ are

$$
\begin{aligned}
\varepsilon_{n} & =O(\log n / n), \\
\Delta \varepsilon_{n} & =O(1 / n) .
\end{aligned}
$$

THEOREM B [2]. The necessary and sufficient conditions that $\sum a_{n} \varepsilon_{n}$ be summable $|C, \alpha|, 0 \leqq \alpha \leqq 1$, whenever $\sum a_{n}$ is summable $|R, \log n, 1|$ are

$$
\begin{aligned}
\varepsilon_{n} & =O\left(n^{\alpha-1} / \log n\right), \\
\Delta \varepsilon_{n} & =O(1 / n(\log n)) .
\end{aligned}
$$

Presented to the Society, January 22, 1970 under the title Some theorems on absolute Nörlund summability; received by the editors March 16, 1971.

AMS 1970 subject classifications. Primary 40D15, 40F05, 40G05.

Key words and phrases. Nörlund summability, summability factors, absolute summability, infinite series.

(c) American Mathematical Society 1972 
THEOREM C [3]. If a series $\sum a_{n}$ is summable $|C, 1|$ and $\left\{p_{n}\right\}$ is a nonincreasing sequence of real and nonnegative numbers, then the series $\sum a_{n}\left(P_{n} / n\right)$ is summable $\left|N, p_{n}\right|$.

THEOREM D [4]. The necessary and sufficient conditions that $\sum a_{n} \varepsilon_{n}$ be summable $|C, \alpha|, 0 \leqq \alpha \leqq 1$, whenever $\sum a_{n}$ is summable $|C, 1|$ are

$$
\begin{aligned}
\varepsilon_{n} & =O\left(n^{\alpha-1}\right), \\
\Delta \varepsilon_{n} & =O\left(n^{-1}\right) .
\end{aligned}
$$

The object of this note is to prove a general theorem which includes, as special cases, all the results stated above. It may be remarked that the proof of our theorem is quite simple and straightforward.

THEOREM. Let $\left(N, p_{n}\right)$ be an absolutely regular method. Let

$$
\begin{gathered}
P_{k} \sum_{n=1}^{\infty}\left|\frac{p_{n+1-k}}{P_{n+1}}-\frac{p_{n-k}}{P_{n}}\right|<C \text { for all } k \geqq 0, \\
P_{n} q_{n}=O\left(Q_{n}\right) .
\end{gathered}
$$

Then the necessary and sufficient conditions for $\sum a_{n} \varepsilon_{n}$ to be summable $\left|N, p_{n}\right|$ whenever $\sum a_{n}$ is summable $\left|\bar{N}, q_{n}\right|$ are

$$
\begin{aligned}
\varepsilon_{n} & =O\left(P_{n} q_{n} / Q_{n}\right), \\
\Delta \varepsilon_{n} & =O\left(q_{n} / Q_{n-1}\right) .
\end{aligned}
$$

We deduce several other interesting results.

COROLlARY I. The necessary and sufficient conditions that $\sum a_{n} \varepsilon_{n}$ be summable $|N, 1 / n+1|$ whenever $\sum a_{n}$ is summable $|R, \log n, 1|$ are

$$
\begin{aligned}
\varepsilon_{n} & =O(1 / n), \\
\Delta \varepsilon_{n} & =O(1 /(n \log n)) .
\end{aligned}
$$

COROLlaRY II. The necessary and sufficient conditions that $\sum a_{n} \varepsilon_{n}$ be absolutely convergent whenever $\sum a_{n}$ is summable $\left|\bar{N}, q_{n}\right|$ are

$$
\begin{aligned}
\varepsilon_{n} & =O\left(q_{n} / Q_{n}\right), \\
\Delta \varepsilon_{n} & =O\left(q_{n} / Q_{n-1}\right) .
\end{aligned}
$$

3. The following lemma is required for the proof of our theorem.

LEMMA [5]. Let $\left\{x_{n}\right\}$ be a sequence of real numbers and let its linear transformation be $y_{n}=\sum_{k=0}^{\infty} a_{n, k} x_{k}$, where $\left(a_{n, k}\right)$ is an infinite matrix. In order that $\sum\left|x_{n}\right|<\infty$ may imply $\sum\left|\Delta y_{n}\right|<\infty$, it is necessary and sufficient 
that

$$
\sum_{n=0}^{\infty}\left|a_{n+1, m}-a_{n, m}\right|<C \text { for } m=1,2,3, \cdots .
$$

4. Proof of theorem. Let $T_{n}=Q_{n}^{-1} \sum_{k=0}^{n} q_{k} s_{k}, x_{n}=T_{n}-T_{n-1}$ and $t_{n}^{*}$ denote the $\left(N, p_{n}\right)$ mean of the series $\sum a_{n} \varepsilon_{n}$, then

and

$$
x_{n}=\frac{q_{n}}{Q_{n} Q_{n-1}} \sum_{k=1}^{n} a_{k} Q_{k-1}
$$

Putting

$$
t_{n}^{*} \equiv y_{n}=P_{n}^{-1} \sum_{k=1}^{n} \frac{Q_{k} Q_{k-1}}{q_{k}} \Delta_{k}\left(\frac{P_{n-k} \varepsilon_{k}}{Q_{k-1}}\right) x_{k}
$$

$$
\begin{aligned}
b_{n, k} & =\left(Q_{k} Q_{k-1} / q_{k} P_{n}\right) \Delta_{k}\left(P_{n-k} \varepsilon_{k} / Q_{k-1}\right), & & k \leqq n, \\
& =0, & & k>n,
\end{aligned}
$$

we have

$$
y_{n}=\sum_{k=1}^{\infty} b_{n, k} x_{k}
$$

Applying the above lemma it follows that $\sum a_{n} \varepsilon_{n}$ is summable $\left|N, p_{n}\right|$ whenever $\sum a_{n}$ is summable $\left|\bar{N}, q_{n}\right|$ if and only if

Now

$$
\sum_{n=1}^{\infty}\left|b_{n+1, k}-b_{n, k}\right|<C \text { for } k=1,2,3, \cdots \text {. }
$$

$$
\begin{aligned}
b_{n+1, k}-b_{n, k}= & \Delta \varepsilon_{k} \frac{Q_{k-1}}{q_{k}}\left(\frac{P_{n-k}}{P_{n+1}}-\frac{P_{n-k-1}}{P_{n}}\right)+\frac{\varepsilon_{k}}{q_{k}} Q_{k}\left(\frac{p_{n+1-k}}{P_{n+1}}-\frac{p_{n-k}}{P_{n}}\right) \\
& +\varepsilon_{k}\left(\frac{P_{n-k}}{P_{n+1}}-\frac{P_{n-k-1}}{P_{n}}\right) .
\end{aligned}
$$

Sufficiency. We have

$$
\begin{aligned}
\sum_{n=1}^{\infty}\left|b_{n+1, k}-b_{n, k}\right| \leqq & \left|\Delta \varepsilon_{k}\right| \frac{Q_{k-1}}{q_{k}} \sum_{n=1}^{\infty}\left|\frac{P_{n-k}}{P_{n+1}}-\frac{P_{n-k-1}}{P_{n}}\right| \\
& +C P_{k} \sum_{n=1}^{\infty}\left|\frac{p_{n+1-k}}{P_{n+1}}-\frac{p_{n-k}}{P_{n}}\right|+\left|\varepsilon_{k}\right| \sum_{n=1}^{\infty}\left|\frac{P_{n-k}}{P_{n+1}}-\frac{P_{n-k-1}}{P_{n}}\right| \\
< & C
\end{aligned}
$$

by the hypotheses of the theorem.

Necessity of (2.9). Since $\sum_{n=1}^{\infty}\left|b_{n+1, k}-b_{n, k}\right|<C$ for all $k$, it follows that the first term, namely for $n=k-1$, must be finite for all $k$. Hence $\varepsilon_{k}=O\left(P_{k} q_{k} / Q_{k}\right)$. 
Necessity of (2.10). Since $\varepsilon_{n}=O(1)$ we have

$$
\begin{aligned}
\left|\Delta \varepsilon_{k}\right| \frac{Q_{k-1}}{q_{k}} \leqq & \left|\Delta_{\varepsilon k}\right| \frac{Q_{k-1}}{q_{k}} \sum_{n=1}^{\infty}\left|\frac{P_{n-k}}{P_{n+1}}-\frac{P_{n-k-1}}{P_{n}}\right| \\
\leqq & \sum_{n=1}^{\infty}\left|b_{n+1, k}-b_{n, k}\right| \\
& +\frac{\left|\varepsilon_{k}\right| Q_{k}}{q_{k}} \sum_{n=1}^{\infty}\left|\frac{p_{n+1-k}}{P_{n+1}}-\frac{p_{n-k}}{P_{n}}\right|+\left|\varepsilon_{k}\right| \sum_{n=1}^{\infty}\left|\frac{P_{n-k}}{P_{n+1}}-\frac{P_{n-k-1}}{P_{n}}\right| \\
< & C
\end{aligned}
$$

for all $k$. Thus $\Delta \varepsilon_{k}=O\left(q_{k} / Q_{k-1}\right)$.

This completes the proof of the theorem.

\section{REFERENCES}

1. G. Das, V. P. Srivastava and R. N. Mohapatra, On absolute summability factors of infinite series, J. Indian Math. Soc. 31 (1967), 189-200. MR 39 \#7321.

2. R. N. Mohapatra, A note on summability factors, J. Indian Math. Soc. 31 (1967), 213-224. MR 39 \#4555.

3. Nand Kishore, On the absolute Nörlund summability factors, Riv. Mat. Univ. Parma (2) 6 (1965), 129-134. MR 36 \#564.

4. A Peyerimhoff, Summierbarkeitsfaktoren für absolut Cesàro-summierbare Reihen, Math. Z. 59 (1954), 417-424. MR 15, 617.

5. G. Sunouchi, Notes on Fourier analysis. XVIII: Absolute summability of series with constant terms, Tôhoku Math. J. (2) 1 (1949). 57-65. MR 11, 654.

Department of Mathematics, Faculty of Engineering, Aligarh Muslim University, Aligarh, INDia 